\title{
COMUNICAÇÃO EDUCATIVA NO CIBERESPAÇO: UTILIZANDO INTERFACES GRATUITAS ${ }^{1}$
}

\section{Educational communication in the cyberspace: utilizing freeware interfaces}

\author{
Alexandra Lilavati Pereira Okada ${ }^{2}$ \\ Edméa Oliveira dos Santos ${ }^{3}$
}

\begin{abstract}
"Comunicar não é de modo algum transmitir uma mensagem ou receber uma mensagem. Isso é a condição física da comunicação, mas não é comunicação. É certo que para comunicar, é preciso enviar mensagens, mas enviar mensagens não é comunicar. Comunicar é partilhar sentido".
\end{abstract}

Pierre Lévy

\section{Resumo}

Neste trabalho, a intenção é refletir sobre a comunicação educativa no ciberespaço, especificamente nos ambientes virtuais de aprendizagem construídos com interfaces gratuitas. Partimos da concepção de ambiente virtual como organização viva, espaço interativo, crítico e colaborativo para aprofundarem alguns conceitos teóricos fundamentados nos novos paradigmas. Neste contexto, apresentamos como construir ambientes virtuais com artefatos gratuitos disponíveis na Web e destacamos a importância do papel do mediador pedagógico como co-autor do espaço de comunicação educativa. Palavras-chave: Comunicação; Interatividade; Ambientes Virtuais de Aprendizagem; Artefatos Gratuitos; Mediação Pedagógica; Co-construção.

1 Este texto foi apresentado na INTERCOM - Sociedade Brasileira de Estudos Interdisciplinares da Comunicação. XXVI. Congresso Brasileiro de Ciências da Comunicação - no GT Comunicação Educativa, BH/MG - 2 a 6 Set. 2003. ale@projeto.org.br

2 Colégio Dante Alighieri e Pontifícia Universidade Católica de São Paulo (PUC-SP).

3 Universidade Federal da Bahia - UFBA. Endereço para correspondência: Av. Princesa Isabel, 334 - Bl.3/806 - 22011-010 - Copacabana, Rio de Janeiro, RJ. mea2@uol.com.br 


\section{Abstract}

In this paper, the intention is to reflect about educational communication in the cyberspace, specifically in virtual leaming environments built with freeware resources. We initiated from the conception of a virtual learning environment as a lively organization, an interactive, critical and collaborative space. In this context, we present how to build virtual learning environments using freeware interfaces available in the web, and we emphasize the importance of the pedagogical mediator as a co-author of this educational communicative space.

Keywords: Communication; Interactivity; Virtual learning environments; Freeware resources; Pedagogical mediation ;Co-construction.

\section{Introdução}

As tecnologias digitais de comunicação e informação estão possibilitando muitas mudanças. As redes não só de máquinas e de informação, mas principalmente de pessoas e de comunidades, estão permitindo configurar novos espaços de interação e de aprendizagem.

Qualquer usuário de qualquer ponto pode não só trocar informações rapidamente com baixíssimo custo, mas reconstruir significados, rearticular idéias individual e coletivamente e, assim, partilhar novos sentidos, socializar saberes e compartilhar novos consensos com todos os usuários da rede. Não há mais emissores e receptores como dois grupos distintos com mensagens estáticas e sim um grande grupo emissor-receptor que pode constantemente reconstruir conhecimentos. A despeito do espaço e do tempo, pessoas podem colaborar, reforçar laços de afinidade e se constituírem como comunidades.

A tradicional concepção de sala de aula, com alunos-expectadores enfileirados diante de um professor-especialista, detentor da informação, deve ser modificada tanto nos ambientes presenciais quanto nos virtuais. Combater o instrucionismo, a reprodução de conhecimentos e fragmentação do saber é o grande desafio. Os novos paradigmas epistemológicos apontam para a criação de espaços que privilegiem a co-construção do conhecimento, o alcance da consciência ético-crítica decorrente da dialogicidade, interatividade, intersubjetividade.

Isto significa uma nova concepção de ambiente de aprendizagem comunidade de aprendizes que se constituam numa nova perspectiva, autoorganização, autonomia, interdependência e conscientização. Neste contexto, é fundamental que os aprendizes sejam sujeitos "cognoscentes". Ou seja, sujeitos que valorizam a ação, a reflexão, a curiosidade, o senso crítico, o questionamento, a inovação. E o professor, por sua vez, deve ocupar o papel de aprendiz e mediador pedagógico, responsável por provocar situações desafiadoras, estimular criticidade, argumentação, desconstrução e reconstrução. 
Para que, assim, a comunidade possa desenvolver as suas habilidades e competências, em busca de inovação, de um saber-fazer novo, mais consciente e crítico articulado com o contexto não só individual, mas global.

Neste sentido, destacamos que os ambientes virtuais de aprendizagem são mais do que um simples conjunto de páginas web. Os ambientes virtuais correspondem a conjunto de elementos técnicos e principalmente humanos e seu feixe de relações contido no ciberespaço (Internet ou Intranet) com uma identidade e um contexto específico criados com a intenção clara de aprendizado cooperativo.

Para compreender os ambientes cooperativos, a partir da Teoria da Autopoiesis apresentada pelos biólogos Maturana e Varela (1980), concebemos os ambientes virtuais de aprendizagem como organismos vivos, redes autopoiéticas.

O termo "autopoiese" foi a palavra mais evocadora que os autores encontraram para anunciar a organização circular do vivo. Para eles, o ser vivo não era simplesmente um conjunto de moléculas. Mas, sim, uma dinâmica molecular singular autônoma resultante de uma rede de interações recursivas internas e externas. Estas inter-relações transcelulares e intracelulares resultam em seu conjunto numa rede molecular autopoiética. Importante dizer que as redes podem ser vistas em suas múltiplas ordens. Como um conjunto inserido em conjuntos mais complexos. Sistemas autopoiéticos de componentes autopoiéticos.

Assim, os ambientes virtuais de aprendizagem vistos como redes autopoiéticas englobam os componentes técnicos (computadores, modem, conectores, servidores web, software, conjunto de sites), todo o conjunto de elementos físicos, biológicos e humanos (associados, membros, colaboradores, mediadores, programadores) e os seus feixes de relações que produzem e os constituem ao gerar as suas próprias dinâmicas de produções.

É este interjogo de interações, ou seja, troca de informações nas diversas interfaces, transmissão digital entre os artefatos computacionais, relações de cooperação e de colaboração estabelecidas entre os participantes que determinam o espaço de existência. Esta configuração dinâmica e específica em cada instante é o que caracteriza o ambiente virtual de aprendizagem como um organismo vivo, um ecossistema colaborativo e interdependente.

Sob o olhar autopoiético, imaginaríamos o ambiente virtual de aprendizagem como sendo o conjunto de artefatos computacionais (páginas web, formulários, portfólios, interfaces síncronas e assíncronas), todos os participantes (professoras, alunos e convidados) e, principalmente, os seus feixes de interações (troca de e-mails, discussões no fórum e na lista de grupos, construção coletiva e individual de textos); enfim, todas as interações ocorridas entre os componentes. 
Assim, partindo dessa visão mais ampla de ambiente virtual de aprendizagem, nos atentaremos aos aspectos técnicos - a utilização de artefatos gratuitos para construir e configurar o site do ambiente e também aos componentes humanos e seus feixes de relações - interatividade e a mediação pedagógica.

\section{Sobre os artefatos gratuitos}

A construção de sites na Internet tem sido uma tarefa cada vez mais fácil. No início da década de 90, para construir uma página web, era necessário ser um bom programador e dominar algumas linguagens (HTML, JAVA ....). Com o rápido desenvolvimento de softwares e aprimoramento dos editores de textos, pessoas sem experiência de programação começaram a desenvolver páginas web e publicá-las em servidores gratuitos da Internet. Inclusive, estes próprios servidores, com intuito de atrair um número cada vez mais de usuários, começaram a oferecer recursos para construção de páginas simples e rápidas em seus próprios sites.

Artefatos gratuitos e práticos para editar e publicar páginas web favoreceram o crescimento extremamente acelerado de homepages e de sites na Internet. O grande número de usuários que também se expande exponencialmente justifica o surgimento de muitos portais de ensino, comunidades de aprendizagem, cidades virtuais do conhecimento, cidadania eletrônica em muitos lugares do mundo.

Segundo o Human Development Report $(2001,6)$, atualmente, mais de 400 milhões de usuários acessam a Internet. Estima-se que em 2005 este número atinja 1 bilhão de pessoas. Em 1993 existiam cerca de apenas 200 websites na Internet, em 2000 foram registrados mais de 20 milhões.

Além do grande número de servidores gratuitos para publicação de páginas web, encontramos vários artefatos também freeware para configuração de interfaces síncronas e assíncronas. Estes artefatos permitem criar fóruns, listas de e-mails, salas de chat, portfólio para arquivos, bancos de dados, formulários, livros de assinaturas e até mesmo comunidades virtuais.

Tais artefatos e servidores gratuitos disponibilizam alguns recursos para personalizar as páginas permitindo a configuração de um design padrão do ambiente, porém, vinculam banners de propagandas e anúncios que podem ser às vezes retirados com um determinado custo mensal.

Contudo, uma das grandes vantagens de utilizar os artefatos gratuitos é possibilitar que os próprios participantes, não só o mediador pedagógico, mas todos os aprendizes construam os seus próprios ambientes de aprendizagem. 
Ou seja, os participantes que são alunos ao utilizarem as interfaces (Lista, Chat, Mural, etc.) e conhecer melhor os artefatos (Yahoo e Scribe...) como usuário, podem tornar-se futuros mediadores e criadores de novos ambientes. Apesar de significar um trabalho maior para os participantes, a utilização de artefatos gratuitos proporciona maior flexibilidade, autonomia e mais conhecimento sobre os recursos técnicos.

A mudança rápida e drástica da tecnologia implica na dependência das versões mais atualizadas e recursos mais avançados favorecendo os eternos contratos anuais para suporte e upgrade... Principalmente quando se trata de ambientes já prontos que não foram construídos pelos sujeitos (tornando verdadeiras caixas pretas).

Devemos ter o cuidado para não tornarmos e nem formarmos usuários dependentes, mas sim sujeitos criativos, críticos e inovadores. A questão não é simplesmente obter os artefatos computacionais mais sofisticados, mas saber fazer a escolha e saber como utilizá-los da melhor forma possível.

Assim, consideramos importante que indivíduos e comunidades (sejam instituições de ensino, professores, grupos de estudos ou pessoas interessadas) possam se informar e ter opiniões próprias sobre as mudanças que ocorrem, selecionar os recursos mais viáveis, tomar decisões conscientes e serem capazes de encontrar os próprios caminhos para a utilização, até mesmo para a criação de seus próprios ambientes virtuais de aprendizagem.

Os tipos de ambientes virtuais de aprendizagem construídos com artefatos gratuitos são bem diversos. Por exemplo, podemos encontrar na web grupos de estudos, aulas interativas, oficinas, conferências, cursos on-line, ambientes virtuais para educação semipresencial, etc.

Artefatos gratuitos, alguns links (Urls):

\section{Tabela 1 - Editores html freeware para construções de sites}

\begin{tabular}{|l|l|}
\hline Netscape Composer & http://cannels.netscape.com/ns/browser/download.jsp \\
\hline FrontPage Express & http://microsoft.com/dowloads/search.asp \\
\hline N estor Web Cartographer & http://www.gate.cnrs.fr/ Zeiliger/nestor/nestor.htm \\
\hline Site com diversos editores & http://www. setarnet.aw/htmlfreeeditors.html \\
\hline
\end{tabular}

\section{Tabela 2 - Servidores para publicação}

\begin{tabular}{|l|l|}
\hline VILA.BOL & http://www.vila.bol.com.br \\
\hline HPG & http://hpg.com.br \\
\hline GEOCITIES & http://www.geocities.com \\
\hline TRIPOD & http://www.tripod.com.br \\
\hline
\end{tabular}




\section{Aspectos relevantes para construção de AVA}

O primeiro ponto que consideramos bem relevante para configuração de ambientes virtuais de aprendizagem é o design simples e fácil. A simplicidade do layout do ambiente possibilita que os participantes aprendam a utilizar a tecnologia enquanto participam do curso. Quanto mais facilidade os participantes tiverem em relação aos aspectos técnicos, mais tempo terão para se envolver com o conteúdo e participar ativamente do ambiente. Palloff e Pratt (1999: 103). Desta forma, os participantes podem reconhecer e compreender o layout do ambiente, perceber as mudanças que ocorrem e onde ocorrem, identificar os locais abertos para participação. É essencial sentir-se capaz e à vontade para "navegar" e "habitar" o espaço virtual. O próprio ambiente favorece a sua ampliação por meio das contribuições dos envolvidos.

Facilidade e simplicidade devem ser definidas considerando a opinião de todos aqueles que irão utilizar o ambiente. Assim, o ambiente pode ser reconfigurado para atender melhor o grupo.

A estrutura pode variar de acordo com a intenção, em síntese:

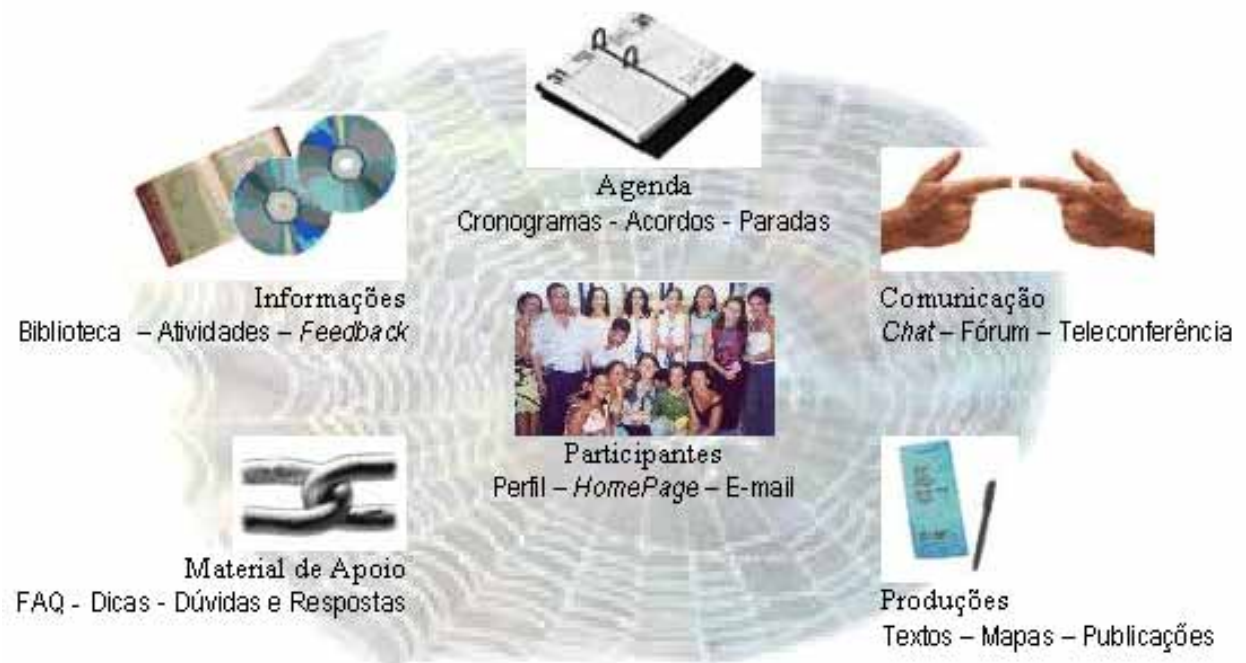

Figura 1 - Design de Ambiente Virtual

Considerando a diversidade da web, destacamos a estética como um fator primordial para um ambiente agradável e atraente. Estética do grego aisthetikós é um conceito associado ao que se pode perceber ou sentir distinguindo o que é belo. Um termo também definido como um estudo das condições e dos efeitos da criação artística quanto a sua conceitualização, diversidade de emoções e sentimentos suscitados no ser humano. 
A estética é um caminho desencadeador de um fenômeno de contágio. Sobre o contágio, Landowiski (1997, p.274) define como um processo que se dá pela estética, em que uma determinada configuração virtualmente atuante é apresentada ao sujeito e passa a fazer parte de seu campo sensitivo. "Neste primeiro momento, é o observado que dá sua forma ao observador, oferecendo-lhe sua própria configuração". A partir daí, que o sujeito descobrirá se consegue projetar-se, deslizar-se, envolver-se, ou seja, se é capaz de deixar-se contagiar.

A estética compreende a escolha das interfaces, o design, a cor, as imagens, símbolos, sons, animações, a disposição do conteúdo, as opções disponíveis em cada página, conexões internas e externas, o mapeamento do espaço virtual.... Apesar da estética ser algo pessoal e particular de cada um, ou seja, subjetivo, é importante que seja também um elemento de consenso. A troca de opiniões e o consenso entre os participantes contribuem para a definição da melhor estética do espaço virtual.

Para compor a estética é importante:

- Ambiente 'clean', não poluído de informações, porém com quantidade suficiente para a sua compreensão.

- Boa navegabilidade que permita o acesso prático, simples, fácil às informações. A definição da barra de navegação é fundamental para evitar que o usuário se perca no meio de dados, nas páginas internas e externas e nas interfaces.

- Design harmonioso, ou seja, equilíbrio nas cores, no tipo de letra, no fundo da página, na escolha das imagens e animação, na definição e disposição da barra de navegação e em outros elementos.

- Padronização suficiente para reconhecer as páginas que fazem parte do ambiente e as que não fazem, definida na escolha de elementos do design que se manterão em todas as páginas. Por exemplo, mesmo utilizando artefatos diferentes, é possível elaborar um ambiente clean, navegável, harmonioso e com identidade padrão.

Além da estética, é fundamental a contextualização. Contextualizar, do latim 'contextu', significa colocar no contexto, situar a si ou alguém em relação a uma determinada circunstância. Colocar um indivíduo a par de algo, de alguma coisa, em algum lugar no tempo e no espaço. Assim, a contextualização possibilita:

- compreender as circunstâncias no qual o ambiente foi criado e as suas futuras transformações;

- compartilhar o significado entre participantes internos e externos;

- construir a identidade do ambiente, conhecer um pouco mais uns aos outros e identificar elementos comuns que permitam uns se identificar com os outros sejam indivíduos ou grupos. 
Inicialmente, isto pode ser realizado pela elaboração do perfil da própria comunidade e de cada participante com fotos, interesses, objetivos, intenções, expectativas e tudo que for interessante para possibilitar a interação. Por exemplo, na página principal do grupo pode conter algumas informações sobre o ambiente: O que é? Por que foi criado? Para quem? Quando surgiu?

Além disso, pode existir uma página sobre quem são os participantes, nome, e-mail, ocupação, página pessoal e sites de interesses.

Mesmo que os artefatos apresentem alguns padrões em relação aos componentes e à diagramação do layout, é importante expressar a identidade do ambiente por meio das opções disponíveis que podem ser configuradas, por exemplo, cores, figuras e textos. Apesar de haver um limite imposto pelo padrão dos formulários, é interessante ficar atento aos espaços não só intratextuais (links internos), mas também extratextuais (links externos, para páginas web de outros sites). Por exemplo, informações que não estão no formulário "padrão" do perfil podem ser encontradas talvez nas páginas pessoais. Todos os detalhes que fazem parte do contexto permitem desvelar um pouco da comunidade, conhecer os participantes, as suas experiências pessoais, as suas histórias de vida. É essencial saber quem somos, quais os nossos dilemas, o que permeiam as nossas práticas, quais as nossas inquietações, o que desencadeiam as nossas interações, as nossas discussões e as nossas investigações.

Outro aspecto importante é a organização do ambiente. A organização, além de proporcionar a boa navegabilidade, permite que as interações e informações sejam agrupadas em assuntos bem definidos. Quando 0 ambiente está bem claro, os participantes registram as mensagens no local certo. Um ambiente bem organizado, além de possibilitar que o usuário não se perca, diante de tantas mensagens, favorece a reflexão e articulação do que já está previamente agrupado.O design do ambiente pode envolver um ou mais artefatos, porém, para que a organização seja a mais adequada, deve atender não só as necessidades do mediador, mas também dos aprendizes.

\section{A importância da interatividade}

Em educação on-line, se a ambiência comunicacional não rompe com a lógica unidirecional própria dos media de massa e dos sistemas de ensino presenciais, pouca ou nenhuma mudança qualitativa acontecerá em termos de educação e, obviamente, de comunicação. Não basta apenas mexer com a forma e com o conteúdo dos materiais ou estratégias de ensino. É necessário modificar o processo de comunicação dos sujeitos envolvidos. P. Blikstein do Media Lab (MIT) pesquisa EaD na Web e chegou à seguinte conclusão: 
Reproduz-se o mesmo paradigma do ensino tradicional, em que se tem 0 professor responsável pela produção e pela transmissão do conhecimento. Mesmo os grupos de discussão, os e-mails, são ainda, formas de integração muito pobres. Os cursos pela internet acabam considerando que as pessoas são recipientes de informação. A educação continua a ser, mesmo com esses aparatos tecnológicos, o que ela sempre foi: uma obrigação chata, burocrática. Se você não muda o paradigma, as tecnologias acabam servindo para reafirmar o que já se faz. (BLIKSTEIN, 2001).

Essa constatação tão precisa é preocupante, pois o papel do professor nos ambientes virtuais de aprendizagem vem se mantendo no mesmo paradigma da transmissão ou da distribuição em massa. O que se tem em geral é a banalização da educação (seja presencial, a distância, ou semipresencial) e subutilização do ciberespaço. É urgente enfrentar esse grave problema criando-se espaços arejados de debate, bem agora quando o MEC promulga a portaria 2253 de outubro/2001, determinando que até $20 \%$ das disciplinas de qualquer curso de graduação credenciado seja ministrado na modalidade a distância.

Não basta apenas criar um site e disponibilizá-lo no ciberespaço. Por mais que o mesmo seja hipertextual, é necessário que seja interativo. É a interatividade com o conteúdo e com seus autores que fazem um site ou software se constituir como um Ambiente Virtual de Aprendizagem - AVA. A interatividade aqui entendida no sentido de Silva:

A disponibilização consciente de um mais comunicacional de modo expressivamente complexo, ao mesmo tempo atentando para interações existentes e promovendo mais e melhores interações - seja entre usuários e tecnologias digitais ou analógicas, seja nas relações "presenciais" ou "virtuais" entre seres humanos. (SILVA, 2000, p.20).

Para que o processo de troca e partilha de sentidos possa ser efetivo, poderemos criar interfaces síncronas a exemplo dos chats ou salas de batepapos e assíncronas a exemplo dos fóruns e listas de discussão. Podemos contar também com os blogs que, além de permitir comunicação síncrona e assíncrona, agrega em seu formato hipertextual uma infinidade de linguagens e forma de expressão.

\section{Os chats}

Os chats possibilitam que os participantes se comuniquem em tempo real. Nessa modalidade de comunicação, todos os participantes podem se 
comunicar com todos que estiverem conectados pelo ambiente virtual de aprendizagem. Além de possibilitar uma comunicação todos-todos, essa interface também permite uma comunicação on-line mais reservada com qualquer participante - um-um.

No ciberespaço, os chats são canais de comunicação que possibilitam as pessoas se comunicarem em tempo real sem nenhuma referência a priori do outro. A comunicação no ciberespaço começa a partir da identificação com o que o outro escreve, com suas idéias, não tendo como referências questões de aparência física, gênero, raça, sexualidade, enfim, caractenísticas que comumente condicionam a sociabilidade em ambientes presenciais. A possibilidade de interação com outros sujeitos sem o contato físico, face a face, permite que novas sociabilidades possam emergir, proporcionando ao sujeito novas e diferentes vivências e situações, tendo como limite seu próprio imaginánio.

As potencialidades da imaginação e sociabilidades podem ser simplificadas devido à natureza da própria intencionalidade de um curso formal. Nos chats livres, os sujeitos entram nas discussões se identificando apenas por um apelido, nickname, já nos ambientes de cursos, as pessoas entram na discussão se identificando pelo nome, podendo ser reconhecido pelo perfil apresentado na identificação de cada participante do curso. O espaço basicamente é usado para reuniões e encontros do grupão ou de grupos de trabalho para discutir questões normalmente referentes à temática proposta pelo curso. Obviamente não é a interface que vai determinar o nível de interações e seus conteúdos e sim a dinâmica comunicativa que a comunidade desenvolverá.

Interfaces, como os chats, permitem que as distâncias geográficas, simbólicas e existências possam ser (re)significadas, permitindo a troca de saberes, desejos, dúvidas a qualquer espaço/tempo, não possíveis em práticas educacionais mediatizadas pelos suportes de comunicação de massa.

\section{Os fóruns}

A interface fórum permite o registro e a comunicação de significados por todo o coletivo pela tecnologia. Emissão e recepção se imbricam e se confundem permitindo que a mensagem circulada seja comentada por todos os sujeitos do processo de comunicação. A inteligência coletiva é alimentada pela conexão da própria comunidade na colaboração todos-todos. Essa é uma das características fundamentais do ciberespaço.

Obviamente devemos considerar que o coletivo forma uma comunidade virtual. Logo, essa comunidade compõe um mesmo espaço (não lugar) junto com a infra-estrutura técnica que denominamos de ciberespaço. De acordo com Lévy, "Por intermédio de mundos virtuais, podemos não só trocar informações, mas verdadeiramente pensar juntos, pôr em comum nossas memónias e projetos para produzir um cérebro cooperativo". (LÉVY, 1998, p.96). 
A possibilidade de diálogos a distância entre indivíduos geograficamente dispersos favorece a criação coletiva, fazendo com que o ciberespaço seja muito mais que um meio de informação - TV, rádio, etc. A comunicação assíncrona proporciona não só a criação de temas de discussões entre estudantes e professores, mas, sobretudo, a troca de sentidos construídos por cada singularidade. Cada sujeito na sua diferença pode expressar e produzir saberes, desenvolver suas competências comunicativas, contribuindo e construindo a comunicação e o conhecimento coletivamente.

\section{Listas de discussão}

As listas de discussão têm quase as mesmas características do fórum, é utilizada para a comunicação assíncrona, em que todos podem se comunicar com todos. A grande diferença é que as mensagens são socializados no formato do correio eletrônico, não requerendo do usuário o acesso a um ambiente específico no ciberespaço para o envio e recebimento delas. Muitas internautas preferem usar as listas de discussão exatamente pela facilidade de interação via caixa de mensagem. A interface do comeio eletrônica é a mais utilizada pela maioria dos internautas. É mais provável passar um dia sem navegar na www do que não abrir a caixa de mensagens pessoal. Daí é muito mais dinâmico responder e enviar mensagens pelas listas do que pelo fórum. Não é o caso aqui de afimar que a lista de discussão é melhor ou pior que o fórum, são apenas diferentes e é a dinâmica de sentido de cada usuário que definirá qual interface é mais adequada a sua necessidade comunicacional.

Cada comunidade virtual criará sua dinâmica e sua ética comunicacional. Gostaria apenas de destacar que muitas comunidades e ou gestores de AVA vem utilizando mecanismos de vigilância e punição próprias das instituições modernas em nome de uma "netqueta". O ciberespaço e os AVA não devem ser espaços do "não se pode" da fábrica, da igreja, da escola. Obviamente é necessário garantir o direito autoral, o respeito e tolerância, mas nada disso poderá comprometer a convivência com as singularidades e as diferenças e principalmente a liberdade de expressão. No site da UNICAMP, encontramos algumas sugestões para a sociabilidade em fórum e listas de discussão no endereço: http:// www.ifi.unicamp.br/ccjdr/netiqueta/dis.html.

\section{Os blogs}

Por conta da facilidade de acesso e apropriação de interfaces no ciberespaço, muitas ações individuais e sociais vêm se transformando. $\mathrm{O}$ diarismo on-line é um desses movimentos. Muitos sujeitos estão contemporaneamente publicizando suas identidades no ciberespaço, o que antes era apenas 
restrito ao espaço atômico dos diários pessoais, hoje, é socializado para o mundo inteiro pelas interfaces digitais chamadas blogs. Pelos blogs, os sujeitos podem editar e atualizar mensagens no formato hipertextual. Além de disponibilizar textos, imagens, sons a qualquer tempo e espaço, é possível interagir com outros sujeitos, pois o formato blog permite que outros usuários possam intervir no conteúdo veiculado pelo autor do blog que se pluraliza, compondo, assim, uma comunidade virtual, a exemplo do site: Janelas do Mundo http://www.facom.ufba.br/ cibercpesquisa/janelas.

Muitos são os sentidos encontrados nos blogs. Seja por necessidade de expor o espírito narcísico, nômade ou simplesmente comunicacional, qualquer sujeito poderá ser emissor e produtor de sentidos. O que importa é a possibilidade técnica de virtualizar e atualizar polifonias. Essa polifonia de sentidos é expressada por estilos variados de hipertextos e diálogos, exemplos: $\quad$ www.mundissa.com/zel, www.amnesia.tux.nu, www.boneca.blogspot.com, www.tiagoteixeira.com.br/blog/weblog.php.

Interfaces gratuitas, alguns links (Urls):

\section{Tabela 3 - Chats, Salas de Bate-papo}

\begin{tabular}{|l|l|}
\hline Chat do Fórum Mundial de Educação & http://chat.portoweb.com.br/fme1/ \\
\hline Chat da Biblioteca Virtual do CNPq & http://www3.prossiga.br/chat/ \\
ICQ & http://go.icq.com/ \\
\hline Sala de Aula Interativa & http:www.saladeaulainterativa.pro.br/chat \\
\hline
\end{tabular}

\section{Tabela 4 - Fóruns de discussão}

\begin{tabular}{|l|l|}
\hline FORUMNOW & http://www.forumnow.com.br \\
\hline INFORUM & http://inforum.insite.com.br/ \\
\hline
\end{tabular}

\section{Tabela 5 - Listas de discussão}

\begin{tabular}{|l|l|}
\hline MEU GRUPO & www.meugrupo.com.br \\
\hline GRUPOS & www.grupos.com.br \\
\hline Y AHOO & www.yahoo.grupos.com.br \\
\hline GEOCITIES & www.geocities.com \\
\hline ESCRIBE & www.escribe.com/ \\
\hline
\end{tabular}

\section{Tabela 6 - Blogs, Diários on-line.}

\begin{tabular}{|l|l|}
\hline BLOGSPOT & http://www.blogspot.com/ \\
\hline IG & http:://blig.ig.com.Br \\
\hline WEBLOGGER & www.weblogger.com.br \\
\hline
\end{tabular}




\section{Sobre a Mediação Pedagógica}

O grande desafio da mediação pedagógica é gerenciar a complexidade entre os elementos e os seus feixes de interações. O mediador define inicialmente a estrutura do ambiente (conteúdo, interfaces, design, atividades...). Nesta estrutura inicial, são definidos quais os canais de comunicação que estarão disponíveis e, assim, os participantes poderão escolher onde interagir. Para que o ambiente seja um organismo vivo, é fundamental que existam interações entre os participantes. São os feixes de interações entre os participantes que podem ampliar ou atenuar o ambiente e manter a sua existência. E, dependendo das relações entre componentes (aspectos técnicos, quantidade e qualidade das mensagens,...), o ambiente pode se expandir, ou então, se reduzir.

Muitas vezes, as pessoas deixam de freqüentar o ambiente porque ele tem pouca interação, a troca de mensagens é pequena e as interações vão diminuindo cada vez mais. Ou então, pode ocorrer o contrário. Quando existem muitas mensagens para ler e pouco tempo, principalmente quando o conteúdo não é de interesse do grupo, a tendência também é de afastamento do ambiente. Portanto, a mediação pedagógica (cuidadosa e competente) tem um papel de destaque, não somente no sentido de procurar ampliar as interações (mantendo a existência do ambiente), como também, fazer intervenções para garantir conexões de qualidade (desconstrução/construção/ reconstrução do conhecimento). Sobre o papel do mediador pedagógico nos ambientes virtuais, destacamos como relevante:

- Acompanhar as mudanças, detectar o contexto dos alunos (expectativas, intenções, experiências prévias), e atualizar constantemente o ambiente para que as intenções coletivas e individuais sejam alcançadas.

- Incentivar o questionamento, a troca de comentários, de informações, críticas e argumentos; abrir o ambiente virtual para intervenções entre todos, em relação às ações, às produções, às interações dos participantes, buscando, assim, a emergência da diversidade, dos olhares diferenciados.

- Garantir a socialização das informações, dos objetivos e das intencionalidades entre todos os participantes e indicar caminhos para que os participantes identifiquem o que pode ser aprimorado e aprofundado, possibilitando, assim, outras escalas de construção e reconstrução.

- Respeitar o ritmo do aluno, mas numa espera atenta (ou seja, acompanhar o aluno e intervir quando necessário), oferecer suporte, apoio e retorno constante para que os alunos articulem o feedback de suas ações, visando a atingir outros desafios rumo ao objetivo principal.

- Estimular a vontade e o desejo dos participantes, relacionar o assunto principal do curso com os interesses dos alunos, buscando determinar 0 foco para que haja o diálogo contínuo.

- Propiciar oportunidades para que pontos em comum possam emergir entre as pessoas, que a linguagem seja incorporada com o viver, que 
a "distância" seja apenas entre as máquinas e que o ambiente favoreça a proximidade entre as pessoas. Isto significa não só ter habilidade em lidar com as complexidades do ambiente, mas também competência para alcançar os objetivos desejados (individuais e coletivos).

A mediação pedagógica pode contribuir para apoiar e facilitar os sujeitos (indivíduo ou grupo) a se auto-organizarem continuamente. E, assim, favorecer a co-construção, cooperação, colaboração, autonomia e inovação. O comprometimento, a responsabilidade, o envolvimento e a cumplicidade passam a ser decorrências e não mais 0 alvo.

\section{Referências}

BLIKSTEIN. P. Entrevista ao Jornal do Brasil, sobre educação, treinamento a distância e a 'nova economia'. Jornal do Brasil, Educação \& Trabalho, fev.2001.

CASTELLS, M. A sociedade em rede. São Paulo,SP: Paz e Terra,1999.

FREIRE, P. Pedagogia da autonomia. 6. ed. Rio de Janeiro,RJ: Paz e Terra, 1997.

LANDOWISKI, E. Sobre el contagio. In: . Semiótrica, estesis, estética. São Paulo, SP: Educ.1999.

LANDOWISKI, E. Sobre el contagio. In: Paulo,SP: Educ,1999.

. Semiótica, estesis, estética. São

LEVY, P. O que é o virtual. São Paulo, SP: Editora 34, 1996.

MASON, R. Models of Online,1998.Courses. Disponível em: :<http://www.aln.org/ alnweb/magazine/vol2_issue2/Masonfinal.htm>.

MATURANA, H.; VARELA, F. Aárvore do conhecimento. Campinas: 1 Psy. 1995. . Autopoiesisand Cognition: the Realization ofLiving, Reidel,Dordrecht,1980.

PALLOFF, R, PRATT, K. BuildingLearning Communities in Cyberspace. San Francisco: Jossey-Bass,1999.

SANTAELIA, L A crítica das mídias na entrada do século XXI. In: PRADO, José Luiza.A. Crítica das práticas midiáticas: da sociedade de massa às ciberculturas (org.). São Paulo,SP: Hackers,2002.

SILVA, Marco. Sala de aula interativa. Rio de Janeiro,RJ: Quartet, 2000. 